\title{
Commentary
}

\section{What Is Qi?}

\section{James Flowers}

\author{
Level 5, 39 Liverpool Street, Sydney NSW 2000, Australia
}

At a conference of practitioners and scholars of Chinese Medicine held in Australia recently, it was reported that China has, in recent decades, spent an inordinate amount of resources on experiments to determine the existence and nature of Qi. The nub of the report was that China is easing up on this research. The veracity of the claim that these experiments are slowing down for lack of concrete breakthroughs is not confirmed in this article. The quest to define Qi continues, with there being no breakthroughs that we know of.

\section{Qi as Subtle Energy?}

Whether someone in China or anywhere has the Holy Grail hidden from view I cannot say, but in the report by Ohnishi, it is claimed that the effects of Qi (called Ki in Japan) energy can be measured. The question is also posed of what Qi actually is. We are asked to consider what kind of waves make up Qi, infrared perhaps, but not UV. I would argue that Ohnishi is not telling us much and is basing his hypothesis on an assumption. He is assuming that the Qi master Nishino is emitting Qi and that the untrained person in the experiment is not emitting Qi because of the changes in the cancer cells only being observed after exposure to the master's fingers (1).

\section{Defying Categorization into Separate Things}

If we take a historical perspective and look at how Qi has been understood by those who used it as a reference over many centuries, we are told that Qi is everything. The classical belief is that it is contextual. If we are to consider Qi as contextual then what Ohnishi is talking about is only one of its aspects. Qi does not only perform desirable functions like reducing cancer cells, but also undesirable actions. I would argue that Ohnishi needs to qualify his argument. Yes, Qi can be measured, according to his argument, but he is assuming that Qi is only Qi

For reprints and all correspondence: James Flowers, Level 5, 39 Liverpool Street, Sydney NSW 2000, Australia. Tel: +61-2-92835525; Fax: +61-292830395; E-mail: jamesflowers@iprimus.com.au when it performs the role of apparently healing in a medical and technical sense. Ohnishi gives Qi a narrow definition. What about the trees that sway in the breeze? The ancients believed that this was Qi. Again, what makes a flower open, a bee hover, an eagle bestride the clouds. Moreover, it is Qi that makes us fall ill, the cold Qi that makes us shiver, as we succumb to a common cold. The withering glance, the anger that hits others with emotional force, the flutters in lovers' hearts, are all considered to be of Qi. Qi, that which defies definition, is a concept of Eastern philosophy. In this thinking, to narrowly define Qi is considered unnecessary. To say that it can be measured is not unbelievable or fantastic, but it could also be said that Qi can be measured because it was observed that a tree grew more luxuriantly if it was exposed to a certain climate rather than another.

\section{Qi Pregnant with Possibility}

Now what of Ohnishi's experiment? Practitioners of qigong would say that Qi is force for both construction and destruction according to the context. What has caused the changes in the cancer cells? This brings us back to the experiments in China. It is hard to say, but it is in fact very possible that the Qi in the experiment is the waves, as is postulated. Also, it is indeed very plausible that Nishino has the ability to manipulate energy and waves. This has been the aim of certain Qigong masters.

Historically, in the Christian west, it may have been considered that only God had the power to perform seeming miracles like reducing pestilential agents. In the wake of the Enlightenment, science has largely replaced God. Logic and rationality deem that there should be an explanation or a definition. In the pre-modern Chinese world, God featured little, if at all. The workings of nature were explained as the workings of Qi. Qi was all encompassing. It could have been argued that Mr Nishino was able to manipulate Qi through focus and intention. Humans were subject to the workings of Qi as well as being agents of Qi, every person being so in different ways and at different times. If that is extrapolated to 
modernity, scientific circles seek to define the Qi that Mr Nishino is causing the cancer cells to reduce.

That which still defies reason remains an object of curiosity. Qi ranges from the sublime as in the formation of the cosmos to the inane as in a butterfly beating its wings. The yawn of a hippopotamus to the clap of thunder that sends a myriad of creatures scurrying would be considered the workings of Qi. For the pre-modern Chinese, Qi comprised both yin and yang, with duality and interdependence in operation. In this reasoning, Mr Nishino's Qi was only potent in relation to the cancer cells. Qi is about relationships and patterning. Potency cannot exist without impotency. If the cancer cells were considered to represent a negative force, then a positive force must be somewhere. Humans claim to be conscious beings. If this is so, then what are humans but Qi that is conscious of self. If humans are conscious of Qi and comprised Qi, then Mr Nishino was using Qi to transform itself.

\section{Qi as a Manifestation of Self-Cultivation}

A central medical classic. The Yellow Emperor's Inner Canon teaches us: 'It is from, calm, indifference, emptiness, and nondesiring that true qi arises. If the spirit is harboured inside, whence can illness arise? When the will is at rest and wishes little, when the heart is at peace and fears nothing, when the body labours but does not tire, then qi flows smoothly from these states, each part follows its desires, and the whole gets everything it seeks' (3).

Judith Farquhar and Qicheng Zhang say of this quote, 'read in the light of the qi-pervaded cosmos that grounds the metaphysics of all classical medical literature, we get a vision of a body living in accord with the broad Way of spontaneous being ...' (3). Or to put it in another way, humans are a part of the cosmic mosaic, moving within the realms of ever fluid nature. In this pre-modern Chinese conceptualization, the more in harmony one is with him or herself and the mind calm, the more potent will be the Qi of that person. Equanimity and calm make for potency of the Qi. In simple terms, efficacy is enhanced if one is focussed, devoid of distractions and nonproductive thoughts. With the merging of one's being with the external world without struggle, one's Qi is said to assume potency and efficacy. Whether this translates into production and emission of rays is yet to be proven, if it ever will be. We have still not defined Qi. Hall and Ames write that Qi might be considered the classical Chinese alternative to the largely unconscious qualitative and atomistic assumptions that began for western culture in classical Greece and continue to shape our commonsense (4). The Chinese philosopher, Mencius (372-289 BC) described Qi in terms of moral energy, related to human excellence.

Others would argue that Qi is not neutral and that if Qi is emitted by a practitioner it is not a fait accompli that the Qi, whatever it is defined as, is something desirable or simply a benign force. Who can really know what is being emitted? For example, chemotherapy or radiotherapy can reduce cancer cells, but are not necessarily something that one would desire as a treatment in the absence of cancer. If this reasoning is followed, it makes it even more problematic what Mr Nishino was actually doing. This reinforces the argument that Qi is contextual, fluid in nature and not a fixed entity.

\section{References}

1. Ohnishi ST, Ohnishi T, Nishino K, Tsurusaki Y, Yamaguchi M. Growth inhibition of cultured human liver carcinoma cells by Ki-energy (lifeenergy): scientific evidence for Ki-effects on cancer cells. Evid Based Complement Altern Med 2005;2:387-93.

2. Ames RT, Hall DL. Focusing the Familiar. Honolulu: University of Hawai'i Press, 2001.

3. Farquhar J, Zhang Q. Biopolitical Beijing: Pleasure, Sovereignty and SelfCultivation in Beijing's Capital Cultural Anthropology. Academic Research Library, 2005.

4. Hall DL, Ames RT. Anticipating China. Albany: State University of New York Press, 1995.

5. Hall DL, Ames RT. Thinking from the Han. Albany: State University of New York Press, 1998.

6. Jullien F. The Propensity of Things. New York: Zone Books, 1999.

7. Kuriyama S. The Expressiveness of the Body. New York: Zone Books, 1999.

8. Lloyd G, Sivin N. The Way and the Word. New Haven: Yale University Press, 1999.

9. Unschuld PU. Medicine in China. Berkeley: University of California Press, 1985.

Received September 8, 2006; accepted September 18, 2006 


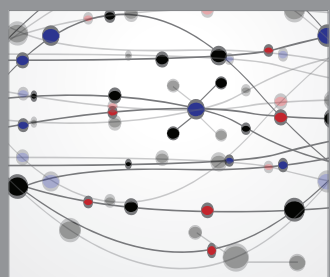

The Scientific World Journal
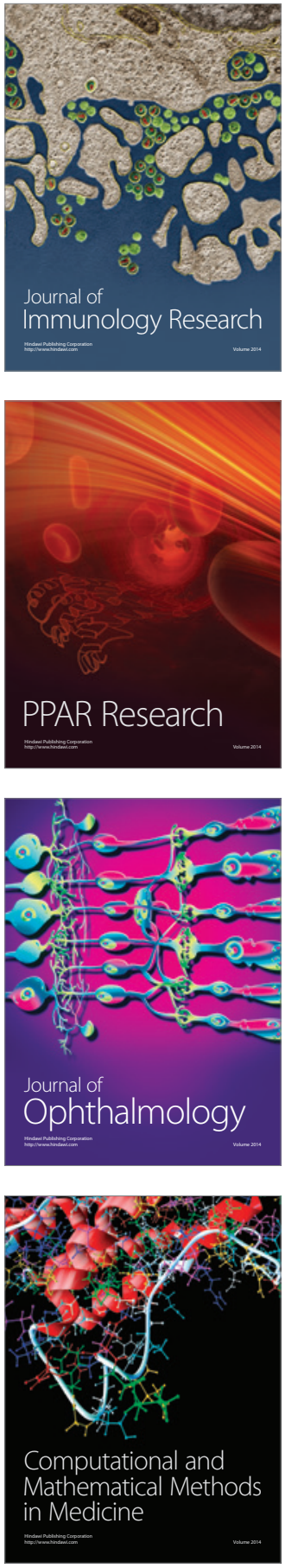

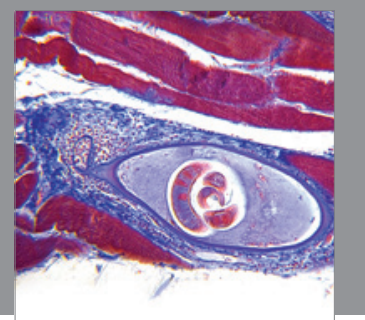

Gastroenterology

Research and Practice
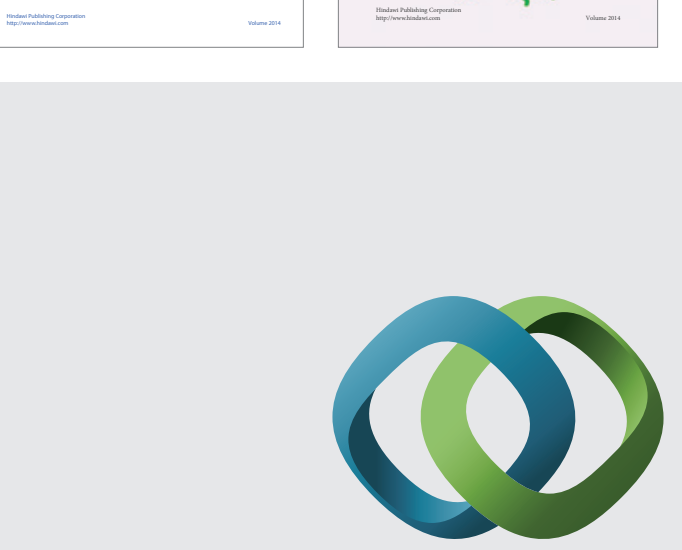

\section{Hindawi}

Submit your manuscripts at

http://www.hindawi.com
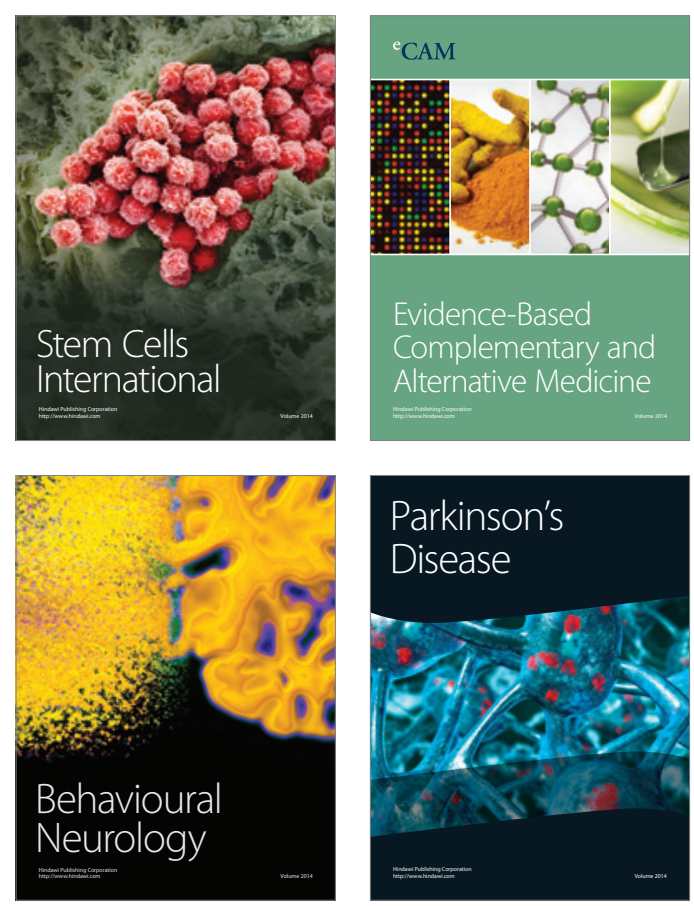

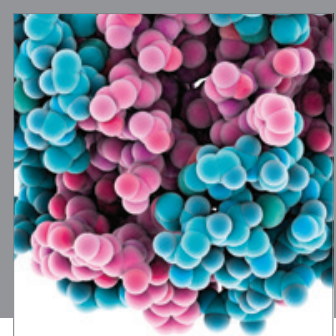

Journal of
Diabetes Research

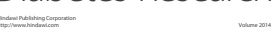

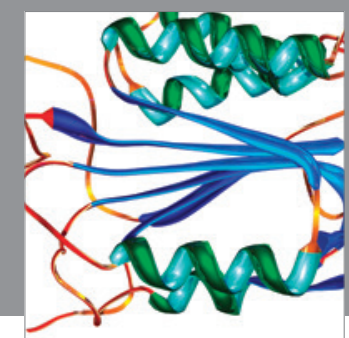

Disease Markers
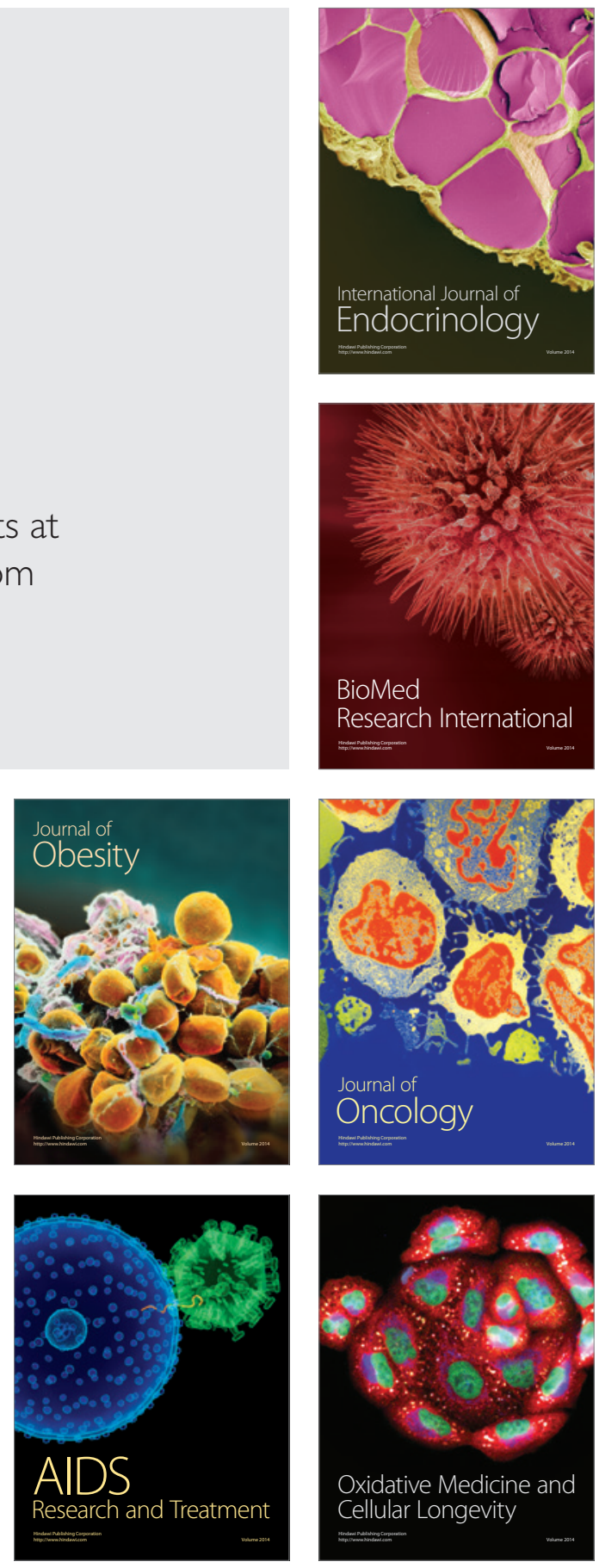